Check for updates

Cite this: RSC Adv., 2018, 8, 2034

\title{
Synthesis and properties of a POM-based trinuclear copper(II) triazole framework $\dagger$
}

\author{
Li Xu, Ying Lu, (D)* Liping Huang, Xiaohui Li, Shuang Wang, Zhong Zhang \\ and Shuxia Liu (D)*
}

A novel POM-based trinuclear copper(I) triazole framework, namely, $\left[\mathrm{H}_{2}\left\{\mathrm{Cu}_{6}(\operatorname{trz})_{6}\left(\mu_{3}-\mathrm{OH}\right)_{2}\right\} \mathrm{Mo}_{5} \mathrm{O}_{18}\right] \cdot 3 \mathrm{H}_{2} \mathrm{O}$ (1) was isolated using a hydrothermal method, which displays a 3D network constructed from trinuclear copper(I) units and triazole ligands with $\left[\mathrm{MO}_{5} \mathrm{O}_{18}\right]^{6-}$ anions as templates. 1 has been identified by single crystal X-ray diffraction, elemental analysis, thermogravimetric analysis, powder X-ray diffraction and FTIR. Magnetic studies indicate that antiferromagnetic interactions exist in 1. In addition, 1 exhibits good Lewis acid catalytic activity for the synthesis of cyclohexanone ethylene ketal with $95 \%$ conversion. The HOMO-LUMO gap $\left(E_{\mathrm{g}}\right)$ of 1 is $2.34 \mathrm{eV}$ calculated using the Kubelka-Munk equation $(F h \nu)^{0.5}$, indicating that its forbidden bandwidth belongs to the semiconductor category. Visible-light photodegradation of RhB catalyzed by 1 was investigated, which shows high activity with an above $98 \%$ degradation rate.

Received 5th November 2017 Accepted 26th December 2017

DOI: 10.1039/c7ra12150d

rsc.li/rsc-advances oxidation, giving a conversion rate of $100 \%$. Mondal et al. ${ }^{6 b}$ reported a series of MOFs based on TTC units, which show high activity in the photocatalytic degradation of toxic dye molecules. Furthermore, due to their interesting magnetic properties, TCC clusters have attracted attention in the construction of magnetic high-nuclear clusters and MOFs materials. For an example, Ouellette et al. reported a microporous metal-organic framework constructed with magnetic $\left\{\mathrm{Cu}_{3}\left(\mu_{3}-\mathrm{OH}\right)(\operatorname{trz})_{3}\right\}^{2+}$ building blocks. ${ }^{7}$

Inspired by the properties of POMs and TTC clusters, we explored to encapsulate POMs into the host matrix of MOFs built by TTC units. Firstly, due to the promising catalytic performances of both POMs and TTC units, the obtained POMsbased TTC frameworks may show enhanced catalytic activity by the combination and synergies of the functions of POMs and TTC units. Secondly, the inlay of POMs into the host matrix of MOFs built by TTC units would effectively enhance the stability of both POMs and TTC frameworks, which is an essential prerequisite for practical applications. ${ }^{8}$ Finally, the combination of magnetic TCC units and POMs, interesting magnetic properties may be evoked. Although some POM-based MOFs have been synthesized, to our knowledge, the POM-based MOFs combined POM and TCC units have never been reported. Herein, a POM-based trinuclear-copper(II) triazole framework, $\left[\left\{\mathrm{H}_{2} \mathrm{Cu}_{6}(\operatorname{trz})_{6}\left(\mu_{3}-\mathrm{OH}\right)_{2}\right\} \mathrm{Mo}_{5} \mathrm{O}_{18}\right] \cdot 3 \mathrm{H}_{2} \mathrm{O}$ (1) (trz = 1,2,4-triazole), has been successfully synthesized under hydrothermal condition. The catalytic performance of $\mathbf{1}$ was assessed by choosing the synthesis of cyclohexanone ethylene ketal catalyzed by Lewis acid and visible-light photodegradation of $\mathrm{RhB}$ as testing reactions. In addition, the magnetic property of $\mathbf{1}$ has been investigated.
Key Laboratory of Polyoxometalate Science of the Ministry of Education, College of Chemistry, Northeast Normal University, Changchun, Jilin 130024, China. E-mail: liusx@nenu.edu.cn; Fax: +86-431-85099328

$\dagger$ Electronic supplementary information (ESI) available: IR spectra, PXRD patterns, TG curves, magnetic properties and additional experimental result figures. CCDC 1571612. For ESI and crystallographic data in CIF or other electronic format see DOI: $10.1039 / \mathrm{c} 7 \mathrm{ra} 12150 \mathrm{~d}$ 


\section{Experimental}

\section{Materials and methods}

$(\mathrm{TBA})_{2}\left[\mathrm{Mo}_{6} \mathrm{O}_{19}\right]$ (TBA $=$ tetrabutylammonium) was prepared according to the literature procedures. ${ }^{9}$ Other chemicals were obtained commercially and used without further purification. Crystal morphology was characterized by using a Quanta 250 FEG scanning electron microscope. Fourier transform infrared spectroscopies (FT-IR) were recorded in the range 400$4000 \mathrm{~cm}^{-1}$ on an Alpha Centaurt FT-IR spectrophotometer using $\mathrm{KBr}$ pellets. Single crystal XRD analysis of $\mathbf{1}$ were conducted on a Bruker Smart Apex CCD diffractometer with Mo K $\alpha$ monochromated radiation $(\lambda=0.71073 \AA)$ at room temperature. Powder X-ray diffraction (PXRD) measurements were performed on a Rigaku D/MAX-3 instrument with $\mathrm{Cu} \mathrm{K} \alpha(\lambda=1.5418 \AA)$ radiation in the angular range $2 \theta 3-50^{\circ}$ at $293 \mathrm{~K}$. Thermogravimetric analysis (TGA) was performed on a Perkin-Elmer TGA7 instrument, with a heating rate of $10{ }^{\circ} \mathrm{C} \mathrm{min}{ }^{-1}$ under a nitrogen atmosphere. The magnetic susceptibility data were obtained on a SQUID magnetometer (Quantum Design, MPMS-5) in the temperature range $2-300 \mathrm{~K}$ with applied field of $1000 \mathrm{Oe}$. GC analyses were performed on an Agilent 6820 instrument with a flame ionization detector.

\section{Procedure for catalytic condensation of cyclohexanone and glycol}

The ketalization reaction was performed in a three-necked round-bottomed flask with a given mass of $\mathbf{1}$. Then, reasonable volume ratio of cyclohexanone and ethylene glycol, and cyclohexane were added with magnetic stirring, the device was equipped with thermometer refluxing condenser tube and water segregator in atmospheric pressure in 3 hours. The solution was heated to boil and refluxed until no water flowed off. The resultant solution was distilled and purified. Samples should be taken every half an hour, and the sample should be diluted with acetone, the yield of cyclohexanone ethylene ketal can be measured by GC analysis with sample diluted by acetone.

\section{Procedure for photocatalysis of $\mathrm{RhB}$}

The photodegradation of $\mathrm{RhB}$ is evaluated under Xe light irradiation from high pressure Xe lamp through a typical process: $10 \mathrm{mg}$ of the compound 1 was mixed together with $100 \mathrm{~mL}$ of $10 \mathrm{mg} \mathrm{L}^{-1} \mathrm{RhB}$ solution in a beaker by ultrasonic dispersion for $30 \mathrm{~min}$ until reached the surface adsorption equilibrium on the particles of compound 1 . Then, the mixture was stirred continuously under visible light irradiation. At 0 , $20,40,60,90,120,150,180$ and $200 \mathrm{~min}, 3 \mathrm{~mL}$ of the sample was taken out from the beaker respectively, followed by centrifugation to remove $\mathbf{1}$ and a clear solution was obtained for UV-vis analysis. The UV-vis diffuse reflectance (DR) spectrum of 1 was recorded between 380 and $550 \mathrm{~nm}$. The photodecomposition rate was calculated by the formula: $D(\%)=\left(A_{0}\right.$ $\left.-A_{t}\right) / A_{0} \times 100 \% ; D$ is the degradation rate; $A_{0}$ is the initial absorption; $A_{t}$ is the concentration after a period of reaction time.

\section{Synthesis of 1}

A mixture of $\mathrm{Na}_{2} \mathrm{MoO}_{4} \cdot 2 \mathrm{H}_{2} \mathrm{O}(1.0 \mathrm{mmol}, 0.242 \mathrm{~g})$, (TBA) $)_{2}\left[\mathrm{Mo}_{6}-\right.$ $\mathrm{O}_{19}$ ] (0.5 mmol, $\left.0.638 \mathrm{~g}\right), \mathrm{CuCl}_{2} \cdot 2 \mathrm{H}_{2} \mathrm{O}(0.341 \mathrm{~g}, 2.0 \mathrm{mmol})$, trz $(2.0 \mathrm{mmol}, 0.138 \mathrm{~g})$ was added to distilled water $(10 \mathrm{~mL})$ with stirring. Then the solution was stirred for $0.5 \mathrm{~h}$ and the $\mathrm{pH}$ was adjusted to 5.2 with $1 \mathrm{M} \mathrm{HCl}$ solution. The resulting suspension was transferred to a Teflon-lined stainless-steel autoclave and sealed. After being heated at $170{ }^{\circ} \mathrm{C}$ for five days, it was cooled to room temperature at a rate of $10{ }^{\circ} \mathrm{C} \mathrm{h}^{-1}$. Yellow block crystals of 1 were separated, washed with water and air-dried. Although $(\mathrm{TBA})_{2}\left[\mathrm{Mo}_{6} \mathrm{O}_{19}\right]$ does not appear in the system, but he is essential in the reaction, because we tried not to add it in the system, has not been a product, it is due to (TBA) $)_{2}\left[\mathrm{Mo}_{6} \mathrm{O}_{19}\right]$ was decomposed into $\mathrm{MoO}_{6}$ polyhedron in the reaction system, then, $\mathrm{MoO}_{6}$ polyhedron reactant with the $\mathrm{MoO}_{4}{ }^{2-}$ get the target product 1. Yield: $0.19 \mathrm{~g}$ ( $30 \%$ based on Mo). Anal. calcd (\%) for 1: C 8.76, H 1.23, N 15.33, Cu 23.17, Mo 29.16; found: C 8.80, H 1.22, N 15.32, Cu 23.20, Mo 29.14. IR (solid KBr pellet): 3268(s), 1559(w), 1373(w), 1221(w), 1045.99(w), 936(s), 823(s), 714(s), 602(s), 524(m), $409(\mathrm{~m}) \mathrm{cm}^{-1}$.

\section{Results and discussion}

\section{Synthesis and crystal structure}

The reaction of $\mathrm{Na}_{2} \mathrm{MoO}_{4} \cdot 2 \mathrm{H}_{2} \mathrm{O},(\mathrm{TBA})_{2}\left[\mathrm{Mo}_{6} \mathrm{O}_{19}\right], \mathrm{CuCl}_{2} \cdot 2 \mathrm{H}_{2} \mathrm{O}$, trz and water under hydrothermal conditions generated yellow block crystals of $\mathbf{1}$. Notably, the formation of $\mathbf{1}$ was highly sensitive to the $\mathrm{pH}$ value of the reaction system, which was controlled in the range of 5.2 to 5.5, and 1 could not be obtained outside this $\mathrm{pH}$ range. Although $(\mathrm{TBA})_{2}\left[\mathrm{Mo}_{6} \mathrm{O}_{19}\right]$ does not appear in the composition of $\mathbf{1}$, it is essential for the synthesis of 1. We cannot obtain 1 in the absence of (TBA) $)_{2}\left[\mathrm{Mo}_{6} \mathrm{O}_{19}\right]$. It may be due to (TBA) $)_{2}\left[\mathrm{Mo}_{6} \mathrm{O}_{19}\right]$ decomposed into $\mathrm{MoO}_{6}$ polyhedra in the reaction system, then $\mathrm{MoO}_{6}$ polyhedra react with $\mathrm{MoO}_{4}{ }^{2-}$ yielding the target product 1 . The SEM image showed that 1 was block crystal and its surface was slippy (Fig. S2, ESI $\dagger$ ). The PXRD pattern of $\mathbf{1}$ and the simulated PXRD pattern are shown in Fig. S5, ESI. $\uparrow$ The diffraction peaks on the patterns correspond well in position, confirming that the product is in a pure phase. 1 displayed a trinuclear copper triazole framework with $\left[\mathrm{Mo}_{5} \mathrm{O}_{18}\right]^{6-}$ anions as templates. There are three $\mathrm{Cu}^{2+}$ ions, six trz ligands, one $\left[\mathrm{Mo}_{5} \mathrm{O}_{18}\right]^{6-}$ anion and one coordination water molecule in the basic structural unit of 1 . Three $\mathrm{Cu}^{2+}$ centres are connected by a $\mu_{3}-\mathrm{O}$ and each pair of adjacent $\mathrm{Cu}^{2+}$ was connected by a triazole ligand to form a three core triangular $\mathrm{Cu}_{3}\left(\mu_{3}-\mathrm{OH}\right)(\text { trz })_{3}$ unit (Fig. 1). In the trinuclear copper unit, three $\mathrm{Cu}^{2+}$ centres display distinct coordination environments: $\mathrm{Cu}_{1}$ was coordinated by the $\mu_{3}-\mathrm{O}$ atom, $\mathrm{O}$ atom from $\left[\mathrm{Mo}_{5} \mathrm{O}_{18}\right]^{6-}$ anions and three $\mathrm{N}$ from trz; $\mathrm{Cu}_{2}$ was connected with the $\mu_{3}-\mathrm{O}$ atom, three $\mathrm{N}$ atoms from trz ligands and one $\mathrm{Ow}$ atom. $\mathrm{Cu}_{3}$ was coordinated by the $\mu_{3}-\mathrm{O}$ atom, one $\mathrm{O}$ atom from a $\left[\mathrm{Mo}_{5} \mathrm{O}_{18}\right]^{6-}$ anion and three $\mathrm{N}$ atoms from trz. The average $\mathrm{Cu}-\mathrm{O}$ and $\mathrm{Cu}-\mathrm{N}$ bond distances are 2.151 $\AA$ and $1.994 \AA$, respectively. $\left[\mathrm{Mo}_{5} \mathrm{O}_{18}\right]^{6-}$ anion is constructed by three $\mathrm{MoO}_{6}$ octahedra and two $\mathrm{MoO}_{5}$ polyhedra by corner-sharing connections with $\mathrm{Mo}-\mathrm{O}$ bond lengths in the range of 1.707-2.606 $\AA$. In the structure of 1 , each 

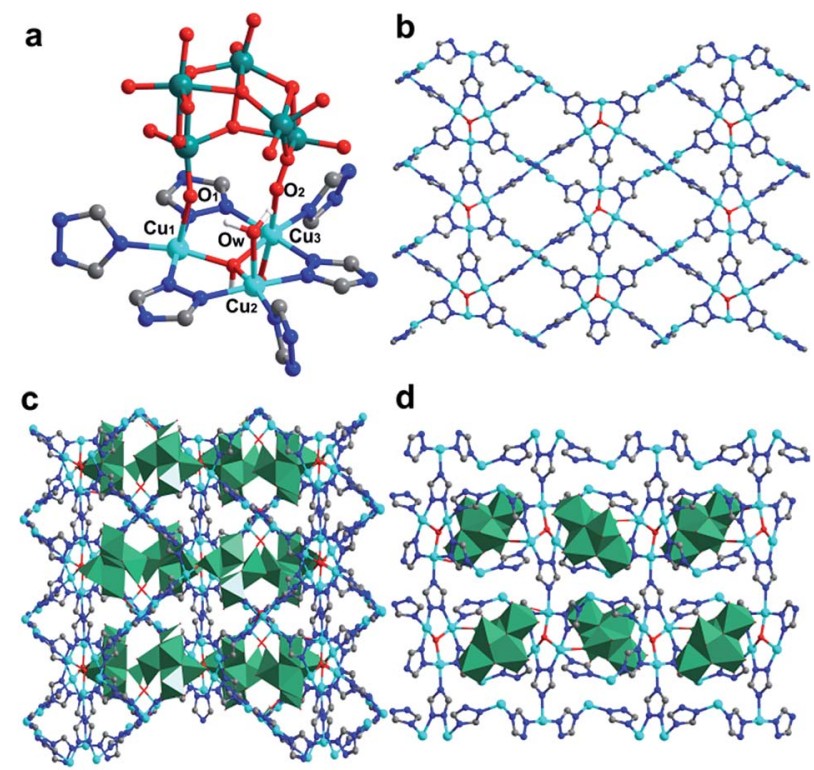

Fig. 1 (a) Diagram of the structural unit of 1. (b) Diagram of the trinuclear copper(॥) triazole framework in compound 1. (c) 3D structure of 1. (d) Diagram of the trinuclear copper(II) triazole framework with $\left[\mathrm{MO}_{5} \mathrm{O}_{18}\right]^{6-}$ guests. Color codes: $\mathrm{MoO}_{6}$ : deep green; O: red; $\mathrm{N}$ : blue spheres; C: gray; Cu: light blue.

$\mathrm{Cu}_{3}\left(\mu_{3}-\mathrm{OH}\right)(\mathrm{trz})_{3}$ unit connects with each other leading to a $3 \mathrm{D}$ trinuclear copper triazole framework with $\left[\mathrm{Mo}_{5} \mathrm{O}_{18}\right]^{6-}$ anions as templates.

\section{Thermal stability}

The stability of $\mathbf{1}, \mathrm{K}_{3} \mathrm{HMo}_{5} \mathrm{O}_{17}$ (ref. 10) and $\mathrm{Cu}_{3}(\operatorname{trz})_{3}(\mathrm{OH})_{3}\left(\mathrm{H}_{2} \mathrm{O}\right)_{4}$ (ref. 6) was initially researched by means of thermogravimetric analysis (TGA). For 1, a gradual mass loss of 3.7\% between 38$330{ }^{\circ} \mathrm{C}$ is assigned to the loss of two crystal lattice $\mathrm{H}_{2} \mathrm{O}$ and one coordinated $\mathrm{H}_{2} \mathrm{O}$ (calcd $3.3 \%$ ). Then, $51.3 \%$ weight loss occurs in the specified temperature region of $450-620^{\circ} \mathrm{C}$, which can be ascribed to the loss of the six triazole ligand and two hydroxyl (calcd 50.6\%), which demonstrates that the main framework of compound 1 was stable until $450{ }^{\circ} \mathrm{C}$ (Fig. S6, ESI $\dagger$ ). While $\mathrm{K}_{3} \mathrm{HMo}_{5} \mathrm{O}_{17}$ and $\mathrm{Cu}_{3}(\operatorname{trz})_{3}(\mathrm{OH})_{3}\left(\mathrm{H}_{2} \mathrm{O}\right)_{4}$ were stable until $525{ }^{\circ} \mathrm{C}$ and $350{ }^{\circ} \mathrm{C}$ according their TG curves, respectively (Fig. S7 and $\mathrm{S} 8, \mathrm{ESI} \dagger)$.

\section{Chemical stability}

1 was air-stable because no efflorescence of the crystal was observed. After being steeped in common organic solvents (such as dimethylformamide, dichloromethane, methanol, acetone, hexanone and glycol) for 5 days at room temperature, there were no changes in its PXRD patterns demonstrated that 1 was stable in these organic solvents (Fig. 2a). Furthermore, 1 was stable in acid and basic aqueous solution with $\mathrm{pH}$ range from 2 to 12 (Fig. 2b). In order to compare the chemical stability of $1, \mathrm{~K}_{3} \mathrm{HMo}_{5} \mathrm{O}_{17}$ and $\mathrm{Cu}_{3}(\operatorname{trz})_{3}(\mathrm{OH})_{3}\left(\mathrm{H}_{2} \mathrm{O}\right)_{4}$, we measured the PXRD patterns of $\mathrm{K}_{3} \mathrm{HMo}_{5} \mathrm{O}_{17}$ and $\mathrm{Cu}_{3}(\operatorname{trz})_{3}(\mathrm{OH})_{3}\left(\mathrm{H}_{2} \mathrm{O}\right)_{4}$ under the same condition (Fig. S9, ESI $\dagger$ ). The result showed that
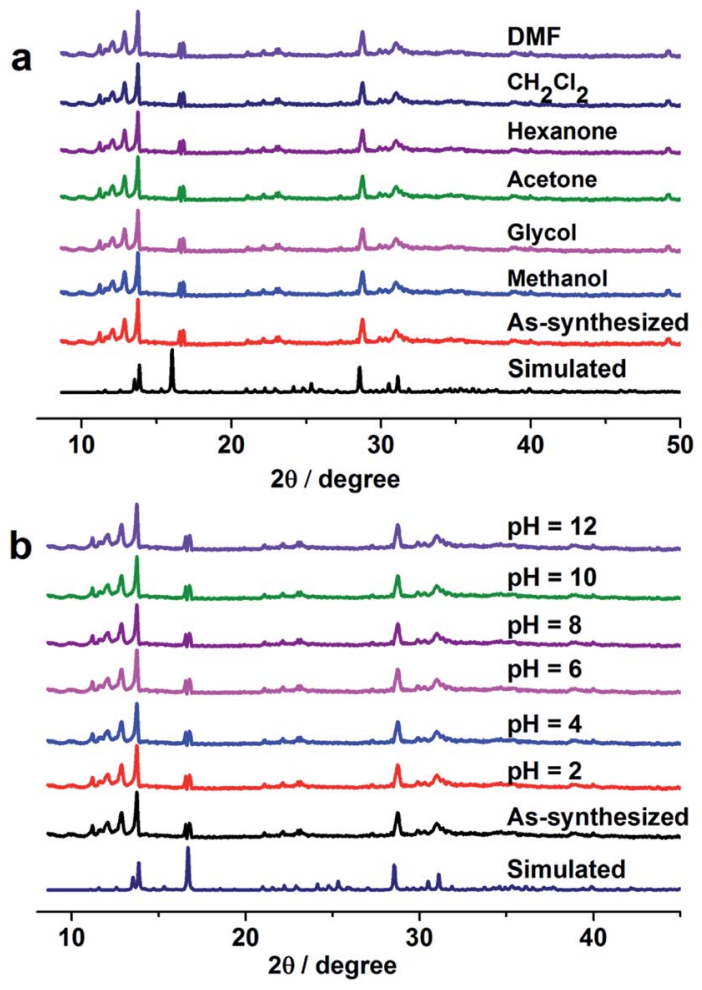

Fig. 2 PXRD patterns of 1: (a) the immersion of 1 in different solvents. (b) The immersion of compound 1 in aqueous solutions with different $\mathrm{pH}$ values.

$\mathrm{K}_{3} \mathrm{HMo}_{5} \mathrm{O}_{17}$ was not stable in glycol and aqueous solution with $\mathrm{pH} \geq 10 . \mathrm{Cu}_{3}(\operatorname{trz})_{3}(\mathrm{OH})_{3}\left(\mathrm{H}_{2} \mathrm{O}\right)_{4}$ was stable in all of these organic solvents, but it was not stable in aqueous solution with $\mathrm{pH} \geq 10$. The above results show that the chemical stability of $\mathbf{1}$ is better than $\mathrm{K}_{3} \mathrm{HMo}_{5} \mathrm{O}_{17}$ and $\mathrm{Cu}_{3}(\operatorname{trz})_{3}(\mathrm{OH})_{3}\left(\mathrm{H}_{2} \mathrm{O}\right)_{4}$, which is attributed to the structure of $\mathbf{1}$, the introduction of POM into TTC MOFs making 1 more stable.

\section{UV-vis spectroscopy}

The UV-vis diffuse reflectance absorption spectrum of compound 1, $\mathrm{K}_{3} \mathrm{HMo}_{5} \mathrm{O}_{17}$ and $\mathrm{Cu}_{3}(\operatorname{trz})_{3}(\mathrm{OH})_{3}\left(\mathrm{H}_{2} \mathrm{O}\right)_{4}$ were tested as presented in Fig. 3, S10 and S11, ESI. $\dagger$ The result showed that their $E_{\mathrm{g}}$ were $2.34 \mathrm{eV}, 2.87 \mathrm{eV}$ and $1.67 \mathrm{ev}$, respectively. We take 1 as model to show the relationship of UV-vis diffuse reflectance absorption spectrum and $E_{\mathrm{g}}$. In the ultraviolet range, the lowest energy band at $265 \mathrm{~nm}$ can be assigned to the charge-transfer transition from $\mathrm{O} \rightarrow \mathrm{Mo}$, the higher energy band at $780 \mathrm{~nm}$ arises from the $\mathrm{d}-\mathrm{d}$ electronic transition of the $\mathrm{Cu}$ centers. ${ }^{\mathbf{1 0}}$ The optical band gaps $\left(E_{\mathrm{g}}\right)$ of $\mathbf{1}$ have been calculated using Tauc's relation: ${ }^{11}(\alpha h \nu)=A\left(h \nu-E_{\mathrm{g}}\right)^{n}$; where $\alpha, \nu, h, n, E_{\mathrm{g}}$ and $A$ stand for absorption coefficient, frequency, Planks' constant, transition coefficient, band gap and band tailing parameter, respectively. Among them, $A$ is a constant and $\alpha$ is the optical absorption coefficient given by the Kubelka-Munk function: $F(R \infty)=(1-$ $R \infty) 2 / 2 R \infty, R \infty=\left(I / I_{\mathrm{o}}\right)_{\text {diff }}$ is the diffuse reflectivity. The index $n$ is a number which characterizes the transition process involved. The intercept of the linear plots $(\alpha h \nu)^{n}$ with the $E$-axis 


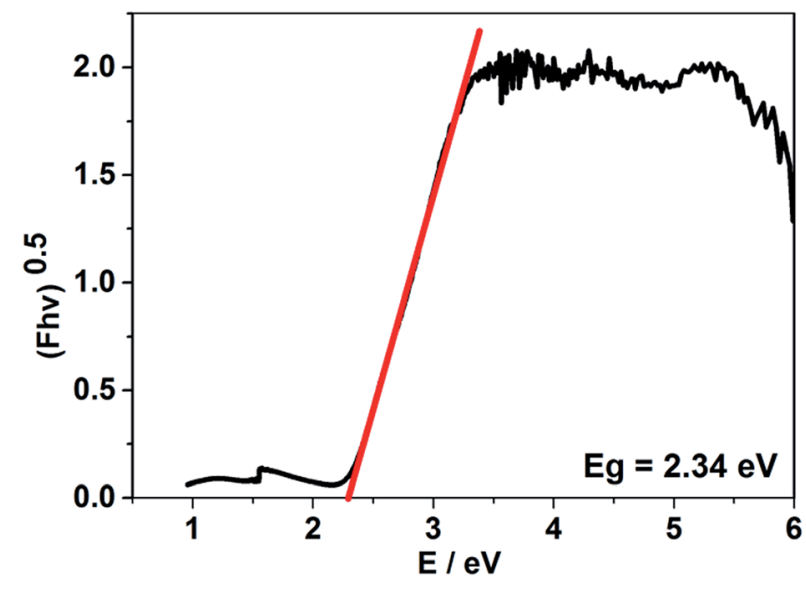

Fig. 3 The diffuse reflectance UV-vis-NIR spectrum of $(F h \nu)^{0.5}$ vs. energy $(\mathrm{eV})$ for $1 . F=(1-R) \times(1-R) / 2 R ; A=\log 1 / R$.

gives a direct transition $(n=1 / 2)$ at $2.34 \mathrm{eV}$ (Fig. 3). The results demonstrate the semiconductor nature for $\mathbf{1}$.

\section{Magnetic property}

The temperature dependence of magnetic susceptibility of $\mathbf{1}$ was investigated at 2-300 $\mathrm{K}$ in an applied magnetic field of 1000 Oe. The $\chi_{\mathbf{M}}$ versus $T$ plot demonstrated the $\chi_{M}$ value slowly increases from $0.0071 \mathrm{emu} \mathrm{mol}^{-1}$ at $300 \mathrm{~K}$ to $0.045 \mathrm{emu} \mathrm{mol}^{-1}$ at $26 \mathrm{~K}$, and then exponentially reaches the maximum value of $0.47 \mathrm{emu} \mathrm{mol}^{-1}$ at $2 \mathrm{~K}$. The $\chi_{\mathrm{M}} T$ value of 1 is $2.13 \mathrm{emu} \mathrm{K} \mathrm{mol}^{-1}$ at $300 \mathrm{~K}$ (Fig. 4), which is larger than the theoretical value of $1.125 \mathrm{emu} \mathrm{K} \mathrm{mol}{ }^{-1}$ expected from three isolated $\mathrm{Cu}^{2+}(S=0.5, g$ $=2.0$ ). As the temperature is lowered, the $\chi_{\mathrm{M}} T$ value decreases slowly up to $50 \mathrm{~K}$ and then sharply falls to a minimum value of $0.94 \mathrm{emu} \mathrm{K} \mathrm{mol}^{-1}$ at $2 \mathrm{~K}$. The temperature dependences of $\chi_{\mathrm{M}}$ and $\chi_{\mathrm{M}} T$ versus $T$ plots for 1 suggest the presence of antiferromagnetic coupling interactions between $\mathrm{Cu}^{2+}$ centers. The $\chi_{\mathrm{M}}{ }^{-1}$ versus $T$ plot follows the Curie-Weiss law with $C=3.56 \mathrm{emu} \mathrm{K}$ $\mathrm{mol}^{-1}$ and $\theta=-29.97 \mathrm{~K}$ in the range of $48-300 \mathrm{~K}$ (Fig. S12, ESI $\dagger$ ), which further demonstrated the presence of antiferromagnetic interactions between $\mathrm{Cu}^{2+}$ ions in 1 . The result was

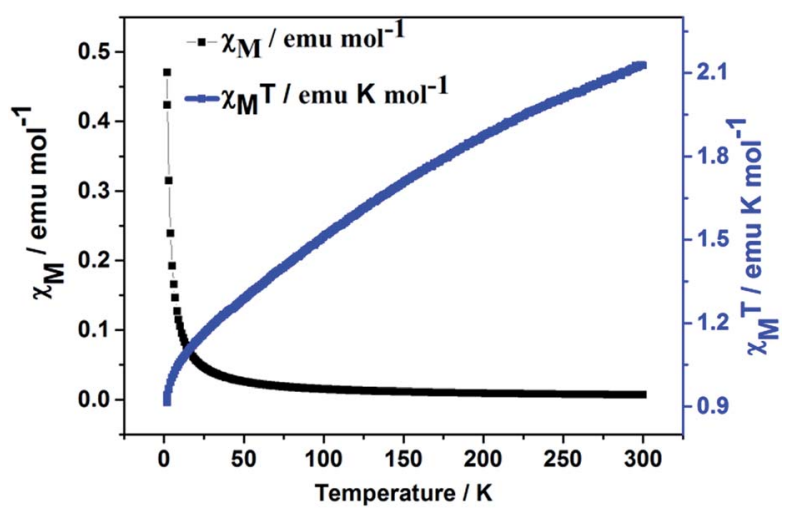

Fig. 4 The plots of $\chi_{M}$ and $\chi_{M} T$ vs. $T$ in the temperature of $2-300 \mathrm{~K}$ for 1. correspondent with the previously report $^{6}$ about TTC compound, antiferromagnetic interactions existing in the TTC core.

\section{Catalysis for condensation reaction of cyclohexanone and glycol}

In many organic reactions, carbonyl protection reaction is one of the most important intermediate processes. Cyclohexanone reacts with glycol to form cyclohexanone ethylene ketal is a typical carbonyl protection reaction, in which acid catalyst plays a significant role. ${ }^{12}$ Herein, we chose the synthesis of cyclohexanone ethylene ketal as a model reaction to research the acid catalytic activity of $\mathbf{1}$. With single factor level analysis, we obtained the optimum reaction conditions of yields of ketals: reaction time were 3.0 hours, cyclohexanone/glycol molar ratio is $1: 1.5$, the amount of acid catalyst 1 was $0.1 \mathrm{~g}$, the most suitable volume of water-carrying agent cyclohexane was $16 \mathrm{~mL}$, reaction temperature was allowed to reflux at 100$105{ }^{\circ} \mathrm{C}$ (Fig. 5). Under the optimum experimental conditions, the yield of cyclohexanone ketal was $95 \%$. The ketal product was characterized by FT-IR (Fig. S13, ESI $\dagger$ ) and PXRD (Fig. S14, ESI $†$ ). After $1 \mathrm{~h}$ of reaction, the catalyst was removed through hot filtration and the filtrate was further heated for $2 \mathrm{~h}$ at $100{ }^{\circ} \mathrm{C}$. No further growth of the conversion (Fig. 5e) indicated
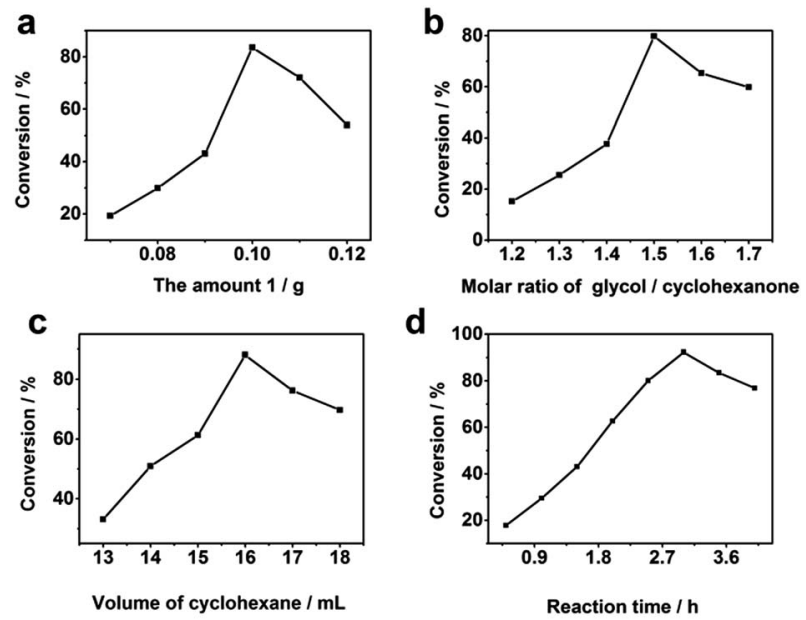

d
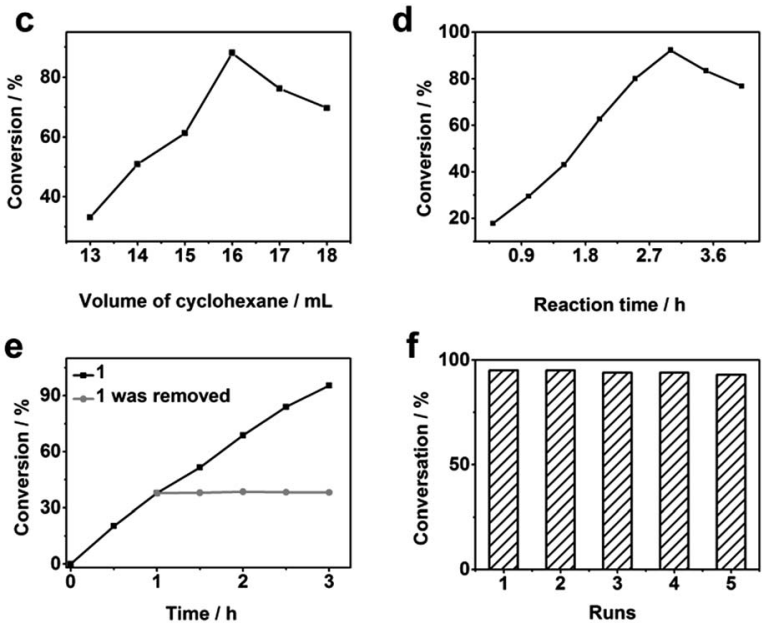

Fig. 5 (a) Effect of the amount of 1 on the yield of cyclohexanone ethylene ketal. (b) Effect of molar ratio of glycol and cyclohexanone on the conversion of cyclohexanone ethylene ketal. (c) Effect of the volume of cyclohexane on the yield of cyclohexanone. (d) Effect of reaction time on the yield of cyclohexanone ethylene ketal. (e) Conversion of cyclohexanone ethylene ketal versus time curves with 1 as catalyst at $100{ }^{\circ} \mathrm{C}$ and catalyst was removed from the suspension after $1 \mathrm{~h}$. (f) The recycle experiments of 1 for the catalytic synthesis of cyclohexanone ethylene ketal. 
that 1 was a heterogeneous catalyst in the catalytic reaction and was not dissolved in the reaction system. 1 was recovered by centrifugation after $3 \mathrm{~h}$ of reaction. The catalyst could be reused for at least 5 times, without significant loss of catalytic activity (Fig. 5f). Additionally, as exhibited in Table 1, compound 1 showed better catalytic activity than the parent materials $\mathrm{K}_{3} \mathrm{Mo}_{5} \mathrm{O}_{17} \mathrm{H}$ and $\mathrm{Cu}_{3}(\mathrm{trz})_{3}(\mathrm{OH})_{3}\left(\mathrm{H}_{2} \mathrm{O}\right)_{4}$, in the presence of which the yield of cyclohexanone ethylene ketal were 95\%, 44\% and $36 \%$, respectively (Table 1 ). The reaction mechanism of the condensation of cyclohexanone and glycol catalyzed by 1 was Lewis acid active sites, which come from unsaturated coordination sites of $\mathrm{Cu}$ centers attack on the carbonyl carbon forming $\mathrm{C}^{+}$ion, and then $\mathrm{C}^{+}$ion accepts the attack of nucleophile glycol forming ketals (Fig. S15†).

\section{Photocatalysis property}

POMs-based coordination polymer was introduced transition metal and organic ligand as functional groups, which could enrich the potential applications of POMs, such as catalysis and conductivity. Some POMs-based coordination polymers have been proven to be an excellent kind of green and cheap photocatalyst and can be used to photodecomposition of organic dyes. ${ }^{13}$ Liu et al. ${ }^{\mathbf{1 3 a}}$ synthesized a POMs-based coordination polymer $\left.\quad\left[\mathrm{WO}_{4} \mathrm{Ni}(\mathrm{en})_{2}\left(\mathrm{H}_{2} \mathrm{O}\right)\right\}_{3}\right]\left[\mathrm{Ni}(\mathrm{en})_{3}\right]\left\{\mathrm{P}_{2} \mathrm{~W}_{18} \mathrm{O}_{62}\right\} \cdot\left[\mathrm{Ni}(\mathrm{en})_{3}\right]$ $\mathrm{CO}_{3} \cdot \mathrm{H}_{2} \mathrm{O}$ (en = ethanediamine), which achieved $97 \%$ degradation rate for the photocatalytic degradation of methylene blue (MB) under visible light irradiation. Luo et $a .^{13 b}$ reported a POMs-based coordination polymer $\left\{\mathrm{Cu}_{2}(\mathrm{~L})_{2}\left[\mathrm{CrMo}_{6}(\mathrm{OH})_{5}{ }^{-}\right.\right.$ $\left.\left.\mathrm{O}_{19}\right]\left(\mathrm{H}_{2} \mathrm{O}\right)_{2}\right\} \cdot 2 \mathrm{H}_{2} \mathrm{O}$ ( $\mathrm{L}=N, N^{\prime}$-bis(3-pyridinecarboxamide)-1,3propane), which exhibited photocatalytic activity on the photodecomposition of RhB under visible light with $97.6 \%$ degradation rate. Herein, we investigated the photodecomposition activity of 1 for RhB. We chose visible light as the light source, because the calculated HOMO-LUMO gap $\left(E_{\mathrm{g}}\right)$ of compound 1 was $2.34 \mathrm{eV}$, which corresponds to visible light absorption. The UV-vis diffuse reflectance spectrum of $\mathbf{1}$ was presented in Fig. 3 and S11, ESI. $\dagger$

The photodegradation rate of RhB by 1 was $98 \%$ in $200 \mathrm{~min}$. After reuse five times, the result did not change evidently

Table 1 Catalytic performances of 1 compared with the reference catalysts for the synthesis of cyclohexanone ethylene $\mathrm{ketal}^{a}$

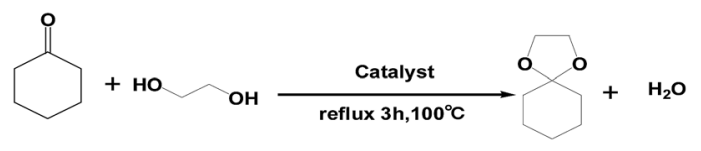

\begin{tabular}{llll}
\hline Entry & Catalyst & Time/h & Yield/\% \\
\hline 1 & $\mathrm{~K}_{3} \mathrm{HMo}_{5} \mathrm{O}_{17}$ & 3 & 44 \\
2 & $\mathrm{Cu}_{3}(\mathrm{trz})_{3}(\mathrm{OH})_{3}\left(\mathrm{H}_{2} \mathrm{O}\right)_{4}$ & 3 & 36 \\
3 & $\mathrm{Compound} \mathrm{1}$ & 3 & 95
\end{tabular}

${ }^{a}$ Reaction conditions: the molar ratio of cyclohexanone to glycol was $1: 1.5$; water-carrying agent: $16 \mathrm{~mL}$ of cyclohexane; reaction temperature: $100-105{ }^{\circ} \mathrm{C}$; the molar ratio of the catalyst was $0.06 \mathrm{mmol}$.
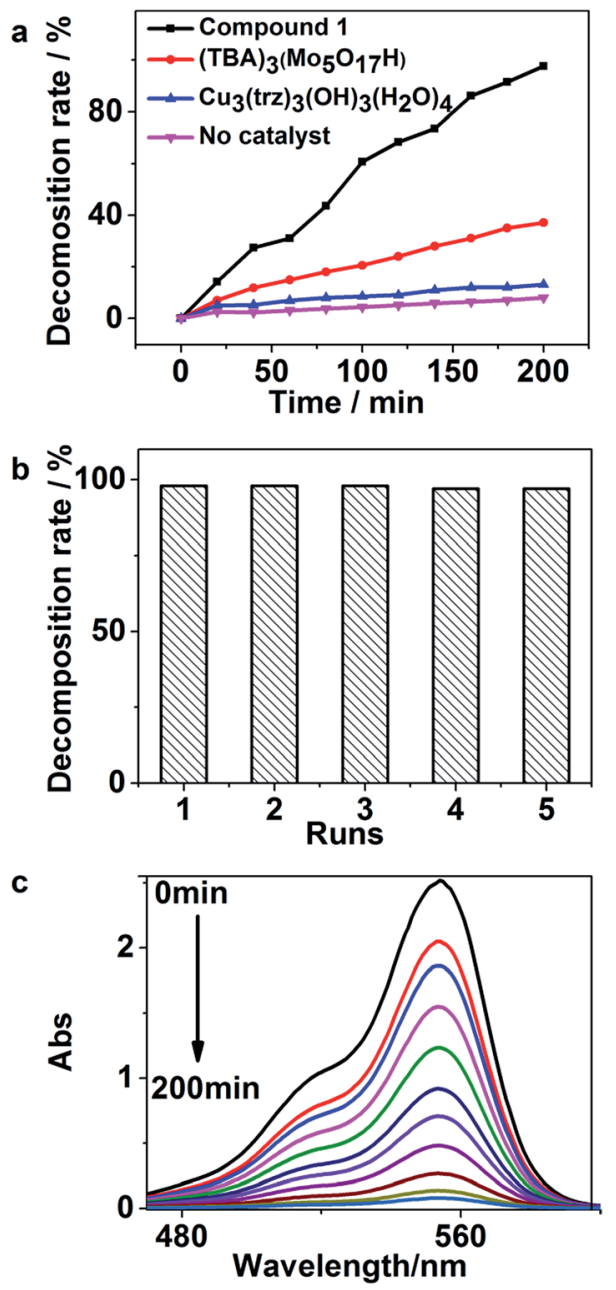

Fig. 6 (a) Absorption spectra of RhB in the presence of 1 under visible light irradiation. (b) Plots of degradation rate versus irradiation time under visible light in the presence of $1,(\mathrm{TBA})_{3}\left[\mathrm{MO}_{5} \mathrm{O}_{17} \mathrm{H}\right], \mathrm{Cu}_{3}(\operatorname{trz})_{3}(-$ $\mathrm{OH})_{3}\left(\mathrm{H}_{2} \mathrm{O}\right)_{4}$ and no catalyst, respectively. (c) The recycle experiments of 1 for the photodecomposition of RhB.

(Fig. 6a and c). For a comparative purpose, the photodecomposition rate in the presence of $(\mathrm{TBA})_{3}\left[\mathrm{Mo}_{5} \mathrm{O}_{17} \mathrm{H}\right], \mathrm{Cu}_{3}(\operatorname{trz})_{3}(-$ $\mathrm{OH})_{3}\left(\mathrm{H}_{2} \mathrm{O}\right)_{4}$ and blank were also measured, respectively. We could find that photodecomposition rates of RhB by (TBA $)_{3}[-$ $\left.\mathrm{Mo}_{5} \mathrm{O}_{17} \mathrm{H}\right], \mathrm{Cu}_{3}(\mathrm{trz})_{3}(\mathrm{OH})_{3}\left(\mathrm{H}_{2} \mathrm{O}\right)_{4}$ and blank were only $37 \%, 13 \%$ and $8 \%$ respectively(Fig. $6 \mathrm{~b}$ ), which were much lower than that by 1 .

We proposed that the photodegradation of RhB by 1 was realized by the synergy effect of $\mathrm{Cu}_{3}(\mathrm{trz})_{3}(\mathrm{OH})_{3}{ }^{2+}$ and $\mathrm{Mo}_{5} \mathrm{O}_{18}{ }^{6-}$ units of 1. The maximum absorbance wavelength of UV-vis diffuse reflectance spectrum of $(\mathrm{TBA})_{3}\left[\mathrm{Mo}_{5} \mathrm{O}_{17} \mathrm{H}\right]$ and $\mathrm{Cu}_{3}(-$ trz $)_{3}(\mathrm{OH})_{3}\left(\mathrm{H}_{2} \mathrm{O}\right)_{4}$ were $280 \mathrm{~nm}$ and $520 \mathrm{~nm}$, respectively (Fig. S9 and $\mathrm{b}, \mathrm{ESI} \dagger)$. Therefore, $\mathrm{Cu}_{3}(\mathrm{trz})_{3}(\mathrm{OH})_{3}{ }^{2+}$ acts as sensitizer absorbing visible light to produce photo-introduced electron. The photo-introduced electron is transferred to the lower LUMO orbit of $\mathrm{Mo}_{5} \mathrm{O}_{18}{ }^{6-}$ and then combined with $\mathrm{O}_{2}$ in air generated $\mathrm{O}_{2}{ }^{-\cdot}$ radical, which acts as oxidizing agent to effectively attack and oxidize RhB molecule. The proposed mechanism was showed in Fig. 7. 


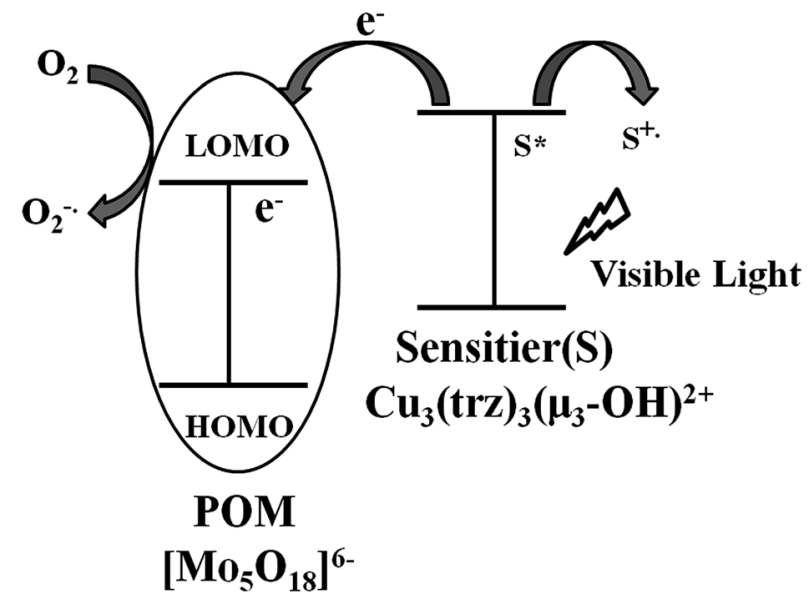

Fig. 7 The proposed mechanism for the photodegradation of RhB by 1 .

\section{Conclusions}

In summary, a new 3D coordination polymer built by triangle trinuclear copper units and triazole with $\left[\mathrm{Mo}_{5} \mathrm{O}_{18}\right]^{6-}$ anions as templates were successfully synthesized. Its catalytic activities in the synthesis of cyclohexanone ethylene ketal and visible light photodegradation of RhB were explored. It exhibits good Lewis acid catalytic activity for the synthesis of cyclohexanone ethylene ketal with 95\% conversion after $3 \mathrm{~h}$. Its forbidden bandwidth belongs to the semiconductor category, and it can catalyze the photodecomposition of RhB under visible-light with above $98 \%$ degradation rate, demonstrating it is an effective catalyst for the removal of organic pollutant under visible light. This work demonstrates that it is a feasible way to achieve POMs-based coordination polymer with excellent catalytic performance by combining catalytic active building blocks. To some degree, this may offer an access to obtain a series of POMs-based catalysts bearing attractive catalytic activities. This continuous research is currently going on in our group.

\section{Conflicts of interest}

There are no conflicts to declare.

\section{Acknowledgements}

This work was supported by the National Natural Science Foundation of China (Grants 91622108, 21371029, 21671033, and 21571030) and the Open Research Fund of the State Key Laboratory of Inorganic Synthesis and Preparative Chemistry (Jilin University, Grant 2015-01).

\section{Notes and references}

1 (a) A. Dolbecq, E. Dumas, C. R. Mayer and P. Mialane, Chem. Rev., 2010, 110, 6009-6048; (b) H. Ji, X. Li, D. Xu, Y. Zhou, L. Zhang, Z. Zuhra and S. Yang, Inorg. Chem.,
2017, 56, 156-166; (c) J. Thiel, C. Ritchie, H. N. Miras, C. Streb, S. G. Mitchell, T. Boyd, M. N. Corella Ochoa, M. H. Rosnes, J. McIver, D.-L. Long and L. Cronin, Angew. Chem., Int. Ed., 2010, 49, 6984-6988; (d) Q.-G. Zhai, X.-Y. Wu, S.-M. Chen, Z.-G. Zhao and C.-Z. Lu, Inorg. Chem., 2007, 46, 5046-5058; (e) Q. Zhai, X. Wu, S. Chen, L. Chen and C. Lu, Inorg. Chim. Acta, 2007, 360, 3484-3492.

2 (a) X.-B. Han, Y.-G. Li, Z.-M. Zhang, H.-Q. Tan, Y. Lu and E.-B. Wang, J. Am. Chem. Soc., 2015, 137, 5486-5493; (b) X.-B. Han, Z.-M. Zhang, T. Zhang, Y.-G. Li, W. Lin, W. You, Z.-M. Su and E.-B. Wang, J. Am. Chem. Soc., 2014, 136, 5359-5366; (c) I. V. Kozhevnikov, Chem. Rev., 1998, 98, 171198; (d) F. Lefebvre, F. X. Liu-Cai and A. Auroux, J. Mater. Chem., 1994, 4, 125-131.

3 (a) C. Duan, M. Wei, D. Guo, C. He and Q. Meng, J. Am. Chem. Soc., 2010, 132, 3321-3330; (b) H. Fu, C. Qin, Y. Lu, Z.-M. Zhang, Y.-G. Li, Z.-M. Su, W.-L. Li and E.-B. Wang, Angew. Chem., Int. Ed., 2012, 51, 7985-7989; (c) Q. Han, C. He, M. Zhao, B. Qi, J. Niu and C. Duan, J. Am. Chem. Soc., 2013, 135, 10186-10189.

4 (a) W. Ouellette, H. Liu, C. J. O'Connor and J. Zubieta, Inorg. Chem., 2009, 48, 4655-4657; (b) T. Afrati, C. Dendrinou-Samara, C. Raptopoulou, A. Terzis, V. Tangoulis, A. Tsipis and D. P. Kessissoglou, Inorg. Chem., 2008, 47, 7545-7555; (c) C. Di Nicola, Y. Y. Karabach, A. M. Kirillov, M. Monari, L. Pandolfo, C. Pettinari and A. J. L. Pombeiro, Inorg. Chem., 2007, 46, 221-230; (d) S. Hazra, S. Mukherjee, M. F. C. Guedes da Silva and A. J. L. Pombeiro, RSC Adv., 2014, 4, 4844948457.

5 (a) B. J. Wallar and J. D. Lipscomb, Chem. Rev., 1996, 96, 2625-2658; (b) E. M. Zueva, M. M. Petrova, R. Herchel, Z. Travnicek, R. G. Raptis, L. Mathivathanan and J. E. McGrady, Dalton Trans., 2009, 38, 5924-5932; (c) X. Zhu, J.-W. Zhao, B.-L. Li, Y. Song, Y.-M. Zhang and Y. Zhang, Inorg. Chem., 2010, 49, 1266-1270.

6 (a) S. Su, Y. Zhang, M. Zhu, X. Song, S. Wang, S. Zhao, S. Song, X. Yang and H. Zhang, Chem. Commun., 2012, 48, 11118-11120; (b) S. Bala, S. Bhattacharya, A. Goswami, A. Adhikary, S. Konar and R. Mondal, Cryst. Growth Des., 2014, 14, 6391-6398.

7 W. Ouellette, M. H. Yu, C. J. O'Connor, D. Hagrman and J. Zubieta, Angew. Chem., Int. Ed., 2006, 45, 3497-3500.

8 (a) H.-X. Ma, J. Du, Z.-M. Zhu, T. Lu, F. Su and L.-C. Zhang, Dalton Trans., 2016, 45, 1631-1637; (b) D.-J. Tao, Z.-M. Li, Z. Cheng, N. Hu and X.-S. Chen, Ind. Eng. Chem. Res., 2012, 51, 16263-16269; (c) J.-P. Wang, H.-X. Ma, L.-C. Zhang, W.-S. You and Z.-M. Zhu, Dalton Trans., 2014, 43, 1717217176.

9 M. Che, M. Fournier and J. P. Launay, J. Chem. Phys., 1979, 71, 1954-1960.

10 (a) M. Filowitz, W. G. Klemperer and W. Shum, J. Am. Chem. Soc., 1978, 100, 2580-2581; (b) X. Kuang, X. Wu, R. Yu, J. P. Donahue, J. Huang and C.-Z. Lu, Nat. Chem., 2010, 2, 461-465. 
11 B. Tripathi, P. Bhatt, P. Chandra Kanth, P. Yadav, B. Desai, M. Kumar Pandey and M. Kumar, Sol. Energy Mater. Sol. Cells, 2015, 132, 615-622.

12 U. Beckmann and S. Brooker, Coord. Chem. Rev., 2003, 245, 17-29.
13 (a) Z.-J. Liu, X.-L. Wang, C. Qin, Z.-M. Zhang, Y.-G. Li, W.-L. Chen and E.-B. Wang, Coord. Chem. Rev., 2016, 313, 94-110; (b) Y.-H. Luo, Z.-L. Lang, X.-X. Lu, W.-W. Ma, Y. Xu and H. Zhang, Inorg. Chem. Commun., 2016, 72, 13-16. 